\title{
Evaluation of Propofol and Ketofol Anaesthesia Following Atropine, Diazepam and Fentanyl Premedication in Dogs
}

\author{
P. Thejasree, P. Veena*, N. Dhanalakshmi and K. Veerabrahmaiah \\ Department of Veterinary Surgery and Radiology, College of Veterinary Science, \\ Tirupati (A.P.), India \\ *Corresponding author
}

\begin{tabular}{|l|}
\hline K e y w o r d s \\
$\begin{array}{l}\text { Propofol and Ketofol, } \\
\text { Anaesthesia, Atropine, } \\
\text { Diazepam and Fentanyl } \\
\text { Premedication }\end{array}$ \\
\hline Article Info \\
\hline $\begin{array}{l}\text { Accepted: } \\
\text { 26 October } 2018 \\
\text { Available Online: } \\
10 \text { November } 2018\end{array}$ \\
\hline
\end{tabular}

A B S T R A C T

Twelve dogs of either sex presented to the college clinic with surgical conditions like pyometra, urethral calculi, fractures and mammary tumours were utilized to study the effect of ketofol and propofol after premedication with atropine sulphate, diazepam and fentanyl. The animals were divided into two groups of six animals each. Ketofol (1:1) combination was given intravenously in group I dogs. Propofol @ $6 \mathrm{mg} / \mathrm{kg}$ b.wt. intravenously was given in group II dogs. Induction quality was excellent, smooth and attained sternal recumbency rapidly without struggling in all animals in both groups. Recovery from anaesthesia was smooth and excitement free in both groups. However, slightly prolonged recovery was a consistent observation in propofol group. No significant difference was noticed in $\mathrm{RT}, \mathrm{RR}, \mathrm{PR}$ and $\mathrm{SpO}_{2}$ values between the groups. Nonsignificant increase in HR was recorded in group I dogs. A significant decrease in HR was observed in dogs subjected to propofol anaesthesia. ECG studies did not reveal any abnormality except increase in amplitude of QRS complex duration in both groups. The haematological parameters like $\mathrm{Hb}, \mathrm{PCV}$ were differed significantly within the group and between the groups. However, all the fluctuations were within the normal physiological range. Changes in biochemical parameters like AST, ALT and ALP were significant between the groups and were within the normal physiological range in both groups. Ketofol with atropine, diazepam and fentanyl premedication provided better surgical anaesthesia with smooth induction and rapid, safe and smooth recovery in dogs.

\section{Introduction}

Anaesthesia is an indispensable pre-requisite to most of the surgical interventions, both in humans and animals, so that the surgeon can perform surgical intervention with maximum precision and sagacity. Procedural sedation and Analgesia (PSA) is a sedation technique involving the use of sedatives, dissociative agents and analgesics alone or in combination.
Analgesics are used to treat pain and sedatives and/or dissociative agents are used to alleviate fear and anxiety (Kim et al., 2015). The goals of PSA are to relieve fear and anxiety, provide analgesia, sedation and amnesia as needed for an unpleasant procedure in order to minimize adverse effects of agents, maintain cardiorespiratory functions and control motor behavior. The ideal agents for PSA satisfy all of these goals have a rapid onset and short 
duration, have the same effect irrespective of the route of administration and are reversible, safe at all ages and simple to administer. Because no such ideal single agent exists, PSA agents must be chosen in combination in order to provide as many of the desired goals as possible (Arora, 2008).

Atropine, an anticholinergic agent, blocks muscarinic receptors at the postganglionic terminations of cholinergic fibers in the autonomic nervous system. Atropine increases the incidence of cardiac dysrhythmia and sinus tachycardia in dogs (Young et al., 2009).

Diazepam, a benzodiazepine, has calming, muscle-relaxant and anticonvulsant effects. It is used as a preanaesthetic for relief of skeletal muscle spasm and as an anticonvulsant. It is frequently administered prior to ketamine to prevent seizures and muscle hypertonus (Lumb and Jones).

Fentanyl is a potent synthetic opioid with strong agonist properties at $\mu$ receptors. Fentanyl is an ultra-short acting agent which has a rapid onset of action and is mainly used as an infusion to provide a continuous level of analgesia.

Propofol, a non-opioid, non-barbiturate intravenous sedative-hypnotic agent, has a rapid onset and short duration as well as a smooth induction and recovery. Its adverse effects include dose - related apnoea and cardiovascular depression such as hypotension, decrease of cardiac output and bradycardia.

Ketamine is a non-competitive N- methyl - daspartate receptor antagonist which provides sedation, amnesia and analgesia and has anticonvulsive and neuroprotective properties. Unlike propofol, ketamine causes tachycardia, increased BP and cardiac output. Ketamine is used in trauma and emergency surgical procedures in both humans and animals. These two completely different sedatives mitigate each other's deficits due to their opposing physiological effects (Taboada and Leece 2014). The advantages of using both ketamine and propofol in combination (Ketofol) include analgesia, rapid recovery, preservation of airways and maintenance of spontaneous respiration and haemodyanamic stability (Saeed 2011). It has therefore been suggested that ketofol provides good total intravenous anaesthesia. There is paucity of literature available on combination of above anaesthetic drugs. Therefore in the present study, this combination of drugs was evaluated together for their safety and efficacy to induce general anaesthesia in dogs.

\section{Materials and Methods}

Dogs with various surgical problems belong to different breeds, aged between 3 to 6 years with a body weight ranged between 8 to 46 kgs were utilized for the study. All these dogs were randomly selected and routine clinical and haematological examinations were carried out and those were found to be fit for surgery were utilized for study. All the dogs were withheld food and water for twelve hours prior to administration of anaesthetic drugs. All the dogs under study were premedicated with atropine sulphate ${ }^{1}$ at the dose rate of $0.04 \mathrm{mg} / \mathrm{kg}$ body weight subcutaneously. Ten minutes after premedication, the dogs were sedated with diazepam ${ }^{2}$ at the dose rate of 0.5 $\mathrm{mg} / \mathrm{kg}$ body weight and fentanyl ${ }^{3} @ 0.002$ $\mathrm{mg} / \mathrm{kg}$ body weight intravenously. After premedication, the animals were divided in to two groups of six animals each as follows.

\section{Group I}

Dogs were subjected to ketofol (1:1) anaesthesia intravenously. (A combination of Ketamine and Propofol, each $3 \mathrm{mg} / \mathrm{kg}$ body weight in a single syringe) 


\section{Group II}

Dogs were given propofol ${ }^{4}$ anaesthesia @ 6 $\mathrm{mg} / \mathrm{kg}$ body weight intravenously.

The character of anaesthesia during induction, surgical plane of anaesthesia and recovery was assessed. Physiological parameters like temperature, respiratory rate, pulse rate, heart rate, pulse oximetry values $\left(\mathrm{SpO}_{2}\right)$ and ECG studies were recorded before and at $5,10,15,30,60$ minutes and $2 \mathrm{hrs}$ time intervals of anaesthesia. Haematological parameters ( $\mathrm{Hb}$ and $\mathrm{PCV})$ and Serum biochemical parameters (AST, ALT and ALP) were also estimated at $0,30,60$ minutes and 2 hrs intervals.

\section{Results and Discussion}

The results of this study are presented in tables $1,2,3$ and 4

Ketofol produced smooth, rapid and excitement free induction with a mean value of $21 \pm 0.516$ seconds, compared with the use of propofol alone. Premedication with atropine, diazepam and fentanyl reduced the induction dose of propofol and ketofol significantly and prolonged period of anaesthesia (Kumar et al., 2014 and Tomas et al., 2014). The recovery from anaesthesia was rapid and smooth without struggling in both groups. However, smooth but slightly prolonged recovery was a consistent observation in propofol group in our study, which might be attributed that high dose of propofol, reduced the clearance of fentanyl which is because of inhibition of microsomal enzymes that are responsible for metabolism of fentanyl (Anderoni and Hughes 2009).

In the present study, decrease in rectal temperature was recorded in both groups during anaesthesia and surgery. Hypothermia was probably produced by the sedatives and anaesthetics used, which decreased rectal temperature by depression of thermoregulatory centre, reduced basal metabolic rate and muscle activity, depression of peripheral circulation and vasodilation (Weaver and Raptopoulus 1990 and Thurmon et al., 1994).

A non-significant decrease in respiratory rate was observed in dogs following ketofol anaesthesia, might be due to the respiratory depressant effects of ketamine and /or propofol (Cullen and Reynoldson 1997). A significant decrease in respiratory rate was observed in group II dogs following premedication and induction of anaesthesia. In the present study, severe respiratory depression was a consistent finding up to $2 \mathrm{hrs}$ interval in group II dogs. Propofol caused a decrease in mean respiratory rate by depressing central inspiratory drive and the ventillatory response to arterial $\mathrm{Co}_{2}$ tension. Transient apnoea was observed immediately after propofol induction in group II animals in our study which might be due to the depression of afferent activity from the carotic body was probably the underlying cause of respiratory depression and transitory apnoea (Muir and Gadawski 1998 and Kurum et al., 2013).

A non-significant decrease in pulse rate was observed in ketofol group whereas, a significant decrease in pulse rate was noticed in dogs subjected to propofol anaesthesia. The administration of propofol is generally associated with decrease in pulse rate. This depression is believed to be a dose-dependent lowering of sympathetic tone, in addition to direct negative inotropic and venodilator effects (Taboada and Leece 2014).

A significant increase in heart rate was recorded after administration of anaesthetics in group I animals which might be due to cardiac stimulatory effects of ketamine. 
Table.1 Mean \pm SE values of anaesthetic recovery time (in minutes) in dogs of both groups

\begin{tabular}{|c|c|c|c|}
\hline Parameter & Group I & Group II \\
\hline Time to extubation & $4.17 \pm 0.40^{\mathrm{a}}$ & $3.83 \pm 0.48^{\mathrm{a}}$ \\
\hline Time of raising head & $9.33 \pm 0.71^{\mathrm{a}}$ & $9.50 \pm 0.62^{\mathrm{a}}$ \\
\hline Time to sternal recumbency & 0.86 & $19.00 \pm 4.87^{\mathrm{a}}$ \\
\hline Time to standing & $25.00 \pm 1.83^{\mathrm{a}}$ & 0.28 \\
\hline
\end{tabular}

Table. 2 Variations in mean \pm SE values of different physiological parameters at different time intervals in dogs of both groups

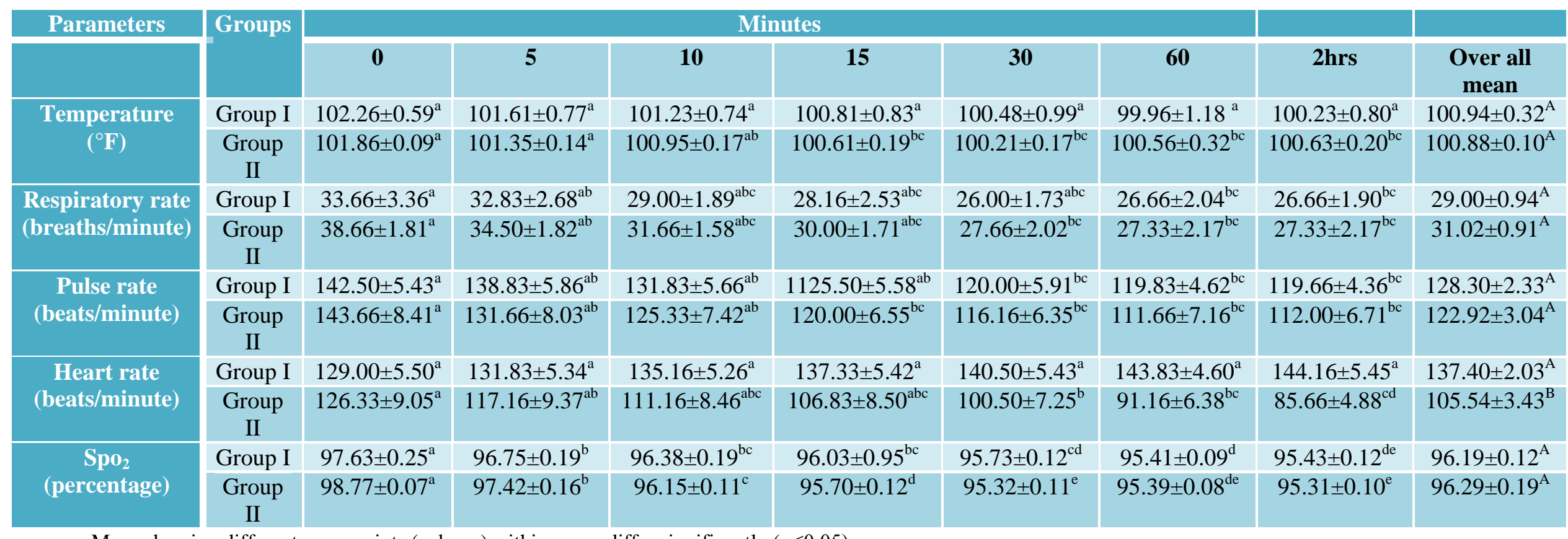

Means bearing different superscripts $(\mathrm{a}, \mathrm{b}, \mathrm{c} .$.$) within a row differ significantly (p \leq 0.05)$

Means bearing different superscripts $(\mathrm{A}, \mathrm{B})$ within a column differ significantly $(p \leq 0.05)$

Group - I: Ketofol

Group - II: Propofol 
Table.3 Variations in mean \pm SE values of different haematological parameters before, during and after anaesthesia in dogs

\begin{tabular}{c|c|c|c|c|c|c|}
\hline Parameters & Groups & \multicolumn{5}{|c}{ Minutes } \\
\cline { 2 - 7 } & & $\mathbf{0}$ & $\mathbf{3 0}$ & $\mathbf{6 0}$ & 2 Hrs & Overall Mean \\
\hline $\begin{array}{c}\text { Haemoglobin } \\
\text { (grams / } \\
\text { percentage) }\end{array}$ & $\begin{array}{c}\text { Group I } \\
\text { II }\end{array}$ & $11.33 \pm 0.42^{\mathrm{a}}$ & $9.83 \pm 0.30^{\mathrm{b}}$ & $9.66 \pm 0.21^{\mathrm{b}}$ & $9.666 \pm 0.21^{\mathrm{b}}$ & $10.12 \pm 0.20^{\mathrm{A}}$ \\
\hline $\begin{array}{c}\text { Packed cell } \\
\text { volume } \\
\text { (Percentage) }\end{array}$ & $\begin{array}{c}\text { Group I } \\
\text { Group }\end{array}$ & $34.00 \pm 1.26^{\mathrm{a}}$ & $29.50 \pm 0.92^{\mathrm{b}}$ & $29.00 \pm 0.63^{\mathrm{b}}$ & $29.00 \pm 0.63^{\mathrm{b}}$ & $30.37 \pm 0.73^{\mathrm{A}}$ \\
\hline
\end{tabular}

Means bearing different superscripts within a row (a, b...) vary significantly $(p \leq 0.05)$

Group I: Ketofol

Group II: Propofol

Table.4 Variations in mean \pm SE values of different biochemical parameters before, during and after anaesthesia in dogs

\begin{tabular}{|c|c|c|c|c|c|c|}
\hline \multirow[t]{2}{*}{ Parameters } & \multirow[t]{2}{*}{ Groups } & \multicolumn{5}{|c|}{ Minutes } \\
\hline & & 0 & 30 & 60 & $2 \mathrm{Hrs}$ & Overall Mean \\
\hline \multirow{2}{*}{$\begin{array}{c}\text { Aspartate amino } \\
\text { transferase }(\mathrm{IU} / \mathrm{mL})\end{array}$} & Group I & $47.11 \pm 5.52^{a}$ & $55.67 \pm 8.27^{\mathrm{a}}$ & $51.55 \pm 6.12^{\mathrm{a}}$ & $49.56 \pm 5.97^{\mathrm{a}}$ & $50.97 \pm 3.12^{\mathrm{A}}$ \\
\hline & Group II & $55.58 \pm 6.47^{\mathrm{a}}$ & $60.43 \pm 9.85^{a}$ & $60.50 \pm 13.38^{a}$ & $57.90 \pm 12.75^{a}$ & $58.60 \pm 5.13^{\mathrm{A}}$ \\
\hline \multirow{2}{*}{$\begin{array}{c}\text { Alanine amino } \\
\text { transferase }(\mathrm{IU} / \mathrm{mL})\end{array}$} & Group I & $29.63 \pm 3.80^{\mathrm{a}}$ & $29.50 \pm 2.15^{a}$ & $31.22 \pm 4.07^{\mathrm{a}}$ & $31.93 \pm 3.49^{\mathrm{a}}$ & $30.57 \pm 1.62^{\mathrm{A}}$ \\
\hline & Group II & $29.11 \pm 3.39^{a}$ & $31.90 \pm 4.32^{a}$ & $37.16 \pm 6.57^{\mathrm{a}}$ & $35.20 \pm 4.97^{\mathrm{a}}$ & $33.34 \pm 2.39^{\mathrm{A}}$ \\
\hline \multirow{2}{*}{$\begin{array}{l}\text { Alkaline phosphatase } \\
\text { (IU/mL) }\end{array}$} & Group I & $78.56 \pm 10.26^{a}$ & $93.39 \pm 15.40^{\mathrm{a}}$ & $93.31 \pm 12.60^{\mathrm{a}}$ & $90.70 \pm 13.10^{\mathrm{a}}$ & $88.99 \pm 6.18^{A}$ \\
\hline & Group II & $72.30 \pm 5.38^{\mathrm{a}}$ & $85.61 \pm 10.29^{a}$ & $87.41 \pm 9.16^{\mathrm{a}}$ & $84.41 \pm 8.11^{\mathrm{a}}$ & $82.43 \pm 4.12^{\mathrm{A}}$ \\
\hline
\end{tabular}

Means bearing different superscripts within a row $(\mathrm{a}, \mathrm{b} . .$.$) vary significantly (p \leq 0.05)$

Group I: Ketofol

Group II: Propofol

This increase in heart rate could be due to increased sympathetic activation associated with the loss of consciousness or a compensatory response to decreased arterial blood pressure caused by arterial vasodilatation (Muir and Gadawski 1998, Kumar et al., 2014).

Significant decrease in heart rate was noticed in dogs anaesthetized with propofol. This might be due to the fact that, fentanyl increases parasympathetic tone and leads to vagally mediated bradycardia with minimal effects in myocardial contractibility. However, these negative chronotropic effects depend on dose and speed of administration
(Huges and Nolan 1999, Gilbert et al., 2003 and Yamashita et al., 2004).

Decrease in $\mathrm{SpO}_{2}$ was seen in animals of both groups throughout the period of observation. This decrease was significant after 10 minutes of drug administration in both groups, which might be due to a certain degree of respiratory depression by the anaesthetics (Kushwaha et al., 2012 and Taboada and Leece 2014).

Electrocardiographic findings in this study showed that ketofol induced tachycardia in dogs with increased amplitude of QRS complex. However, dogs with propofol anaesthesia showed normal heart rate with 
increased amplitude of QRS complex. Increased QRS complex in both groups in our study, indicated delayed ventricular depolarization as reported by Pereira et al., (2001).

In our study, haemoglobin and packed cell volume decreased significantly in both groups during post anaesthetic period. Pooling of circulatory blood cells in the spleen or other reservoirs secondary to decreased sympathetic activity explained the decrease in haemoglobin and packed cell volume. The decrease in haemoglobin and packed cell volume during the period of anaesthesia or sedation might be due to shifting of fluid from extravascular compartment to intravascular compartment in order to maintain normal cardiac output in animals. The decreased haemoglobin and packed cell volume was reported after administration of propofol in dogs (Sear et al., 1985 and Gill et al., 1996),

A non-significant increase in AST, ALT and ALP was noticed in both groups throughout the period of observation, but this increase was within normal physiological limit which indicated the possibility of pathological changes in the liver could therefore, be ruled out. It corroborates with the findings of Bayan et al., 2002 following administration of propofol in dogs.

Propofol (2,6-di-iso propylphenol) is a lipid soluble sedative agent with a little or no amnestic or analgesic potential. It is widely employed emergency department sedation due to the dense sedation provided, rapidity of onset and reliable recovery time with little, if any residual sedation. Potential side effects are hypotension and respiratory depression with hypoxaemia which is dose-related.

Ketamine is a dissociative anaesthetic provides sedation and analgesia. Although a direct myocardial depressant, the clinical effects of ketamine are a rise in blood pressure, and heart rate due to its sympathomimetic action. Ketamine provides profound analgesia and compares favourably to traditional opiates.

Because both agents possess significant advantages and disadvantages, attempts to combine and therefore offset these side effects is an attractive option. A combination of a lower dose of each agent should result in a decreased incidence of unwanted side effects. Our study suggests that compared to propofol, ketofol, a combination of ketamine and propofol in a single syringe to be easy to use and offers excellent procedural sedation and analgesia, a more haemodynamically stable experience due to the sympathomimetic action of ketamine offsetting the propofol effects and the ability to use significantly lower doses of propofol.

Hence it is concluded that the combination of ketamine and propofol (Ketofol) with atropine, diazepam and fentanyl premedication, provides an attractive combination for procedural sedation and analgesia in dogs. Ketofol results in less hypotension, a better quality sedation and better patient comfort and safety with rapid and smooth recovery and therefore, be recommended for anaesthesia in dogs.

\section{References}

Andreoni V and Hughes L J M 2009 Propofol and fentanyl infusions in dogs of various breeds undergoing surgery. Veterinary Anaesthesia and Analgesia 36(6): 523-531.

Arora S 2008 Combining ketamine and propofol ("Ketofol") for emergency department procedural sedation and analgesia. West Journal of Emergency Medicine 9(1): 20-23. 
Bayan H and Konwar B 2014 Clinical evaluation of ketamine-propofol anaesthesia in dog. Indian Journal of Field Veterinarian 10(2): 41-42.

Cullen L K and Reynoldson J A 1997 Effects of tiletamine/zolazepam premedication on propofol anaesthesia in dogs. Veterinary Record 140: 363-366.

Gilbert D B, Motzel S L and Das S R 2003 Post-opertive pain management using fentanyl patches in dogs. Contemporary topics in Lab Animal Science 42(4): 2126.

Gill J R, Rodriguez J F, Ezquerra L J, Vives M A, Jimenez J and Uson J M 1996 Development of anaesthesia and changes in blood parameters in dogs medicated with propofol. Medicina Veterinaria 13: 242-246.

Hughes L J M and Nolan M A 1999 Total intravenous in Grey-hounds: pharmocokinetics of propofol and fentanyl a preliminary study. Veterinary Surgery 28: 513-524.

Kim S, Park W, Lee S, Park W, Jeong S, Jeong M, Ahn T, Kang S and Bae C 2015 The protocol verification of ketamine and propofol combination (Ketofol) by heart rate variability in dogs. Journal of Animal and Veterinary Advances 14(5): 119-124.

Kumar A, Kumar A, Tyagi S P, Sharma S K and Sharma R 2014 Ketofol as a general anaesthesia agent in diazepam or midazolam premedicated and halothane anaesthetized dogs. Indian Journal of Veterinary Surgery 35(1): 31-34.

Kurum B, Pekcan Z, Kalender H, Kumandas A, Mutan O C and Elma E 2013 Comparison of propofol-remifentanil and propofol-fentanyl anaesthesia during ovariohysterectomy in dogs. Kafkas Universitesi Veteriner Fakultesi Dergis pA33 academic Journal 33-39.

Kushwaha J P, Malik V and Singh B 2012 Evaluation of midazolam and propofol in different combinations for clinical anaesthesia in dogs. Indian Journal of Veterinary Surgery 33(2): 77-81.

Lumb W V and Jones E W 1996 Veterinary anaesthesia, edn $3^{\text {rd. }}$ Williams and Wilkins. Baltimore, Maryland USA pp199-202.

Muir WW and Gadawski J E 1998 Respiratory depression and apnoea induced by propofol in dogs. American Journal of Veterinary Research 59(2): $157-61$.

Pereira G G, Larsson M H M A and Yamaky F L 2001 Effects propofol on the electrocardiogram and blood pressure of clinically healthy cats. World Small Animal Veterinary Association world congress - Vancouver: 14-16.

Saeed E 2011 Ketofol Infusion as a procedural sedation and analgesia modality for minor orthopaedic surgeries: evaluation of dose-outcome relation. Ain Shams Journal of Anaesthesiology 4(1): 63-74.

Sear J W, Uppington J and Kay N H 1985 Haematological and biochemical changes during anaesthesia with propofol. Post Graduate Medical Journal 61(3): 165168.

Taboada M F and Leece E A 2014 Comparison of propofol with ketofol, a propofol-ketamine admixture, for induction of anaesthesia in healthy dogs. Veterinary Anaesthesia and Analgesia 41: 574-582.

Thurmon J C, Ko J C H, Benson $\mathrm{G} \mathrm{J}$, Tranquilli W J and Olson W A 1994 Haemodynamic and analgesic effects of propofol in medetomidine premedicated dogs. American Journal of Veterinary Research 55: 363-367.

Tomas L, Igor C, Valent L, Oskar N, Maria K, Csilla T, Alader M, Jana F, Vladimir $\mathrm{P}$ and Slavomir H 2014 Cardiorespiratory and haemodynamic effects of medetomidine or xylazine 
with atropine and diazepam premedication for total intravenous anaesthesia induced and maintained with propofol/fentanyl in dogs undergoing surgery. Acta Veterinaria Beograd 64(4): 466-476.

Weaver B M Q and Raptopoulos D 1990 Induction of anaesthesia in dogs and cats with propofol. Veterinary Record 126: 617-620.

Yamashita K, Adachi Y, Kushiro T, Umar M A, Tsuzuki K, Machara S, Seno T and
Izumisawa Y 2004 Total intravenous anaesthesia with propofol and fentanyl in dogs. Journal of Japan Veterinary Medical Association 57(11): 715-720.

Young P W, Chunsik B, Soohan L and Woodae P 2009 Autonomic nervous system properties of atropine and glycopyrrolate on heart variability during anaesthesia with ketamine, xylazine in dogs. Journal of Veterinary Clinics 26(3): 212-219.

\section{How to cite this article:}

Thejasree, P., P. Veena, N. Dhanalakshmi and Veerabrahmaiah, K. 2018. Evaluation of Propofol and Ketofol Anaesthesia Following Atropine, Diazepam and Fentanyl Premedication in Dogs. Int.J.Curr.Microbiol.App.Sci. 7(11): 3130-3137.

doi: https://doi.org/10.20546/ijcmas.2018.711.359 